\title{
Kentsel Peyzaj Yapılarında Zemin Geçirimliliği Üzerine Bir Araştırma: Tekirdağ Örneği
}

\author{
Aslı KORKUT ${ }^{1}$, Pınar GÜLTÜRK ${ }^{1},{ }^{*}$ Tuğba ÜSTÜN TOPAL ${ }^{1}$ \\ ${ }^{1}$ Namık Kemal Üniversitesi, Güzel Sanatlar, Tasarım ve Mimarlık Fakültesi Peyzaj Mimarlığı Bölümü \\ Değirmenaltı/Tekirdağ \\ *Sorumlu Yazar: tustun@nku.edu.tr
}

Geliş Tarihi: 08.04.2016

\begin{abstract}
Özet
Doğal değerlerin tahribi, hızlı ve plansız kentleşme, küresel ısınma ve iklim değişiklikleri yaşadığımız çevrenin hızla olumsuz yönde değişmesine neden olmaktadır. Özellikle, su kaynaklarının azalmasıyla ortaya çıkan su sorunu, günümüzde küresel bir çevre sorunu haline gelmiştir. İnsanoğlunun kentsel yaşam adına değiştirdiği ve dönüştürdüğü çevrede yeşil alanlar sürekli azalırken, betonlaşmaya bağlı geçirimsiz zemin oluşumları her geçen gün artmaktadır. Geçirimsiz zeminler nedeniyle, yağış sularının toprağa sızarak yer altı sularının beslenmesi engellenmekte, bu suların yüzey drenajı ile kanalizasyon sistemine ya da akarsulara karışmasına yol açılmaktadır. Diğer taraftan, son yıllarda dünya gündeminde önemli bir yere sahip olan küresel iklim değişikliğini kentleşme daha fazla tetiklemekte, buna bağlı olarak hissedilebilir sıcaklıklar artarak kentsel ısı adası etkisi ortaya çıkmaktadır.

Buradan yola çıkılarak, bu çalışma, kent dokusunda zemin geçirimliliği durumunu ortaya koymak amacıyla Tekirdağ örneğinde yapılmıştır. Çalışmada, Tekirdağ kenti içinde, farklı peyzaj yapılarını içinde barındıran bir alan seçilerek zeminlerin geçirimlilik açısından mevcut durumları irdelenmiştir.

Araştırma sonucunda elde edilen \%57.5oranındaki geçirimsiz zeminin, uluslararası kriterlerin oldukça üzerinde olduğu saptanmıştır. Bu da, Tekirdağ kent dokusunda mikro ölçekli bir alan örneğinde, geçirimli yüzeylerin yeterli olmadığını, bu nedenle kentsel 1sı adası etkisinin bertaraf edilmesi, hidrolojik su döngüsünün sağlanması, canlı yaşam mekanı oluşturma gibi çevresel katkıların yeterince sağlanamadığını ortaya koymaktadır. Bu hususta, mevcut durumun iyileştirilmesine yönelik öneriler sunulmuştur.
\end{abstract}

Anahtar Kelimeler: Kent, Kentsel peyzaj yapıları, Geçirimli zeminler, Geçirimsiz zeminler, Tekirdağ

\section{A Study on Ground Permeability of the Urban Landscape Structures: The Case Study of Tekirdă}

\begin{abstract}
The destruction of natural environments, rapid and unplanned urbanization, global warming and climate change have caused to change the environment where we live in negatively. In particular the water problem that is occurred by the reduction of water resource has become a global environmental problem. While green areas are decreasing continuously by the effect of human beings' interchange and transformation on the behalf of urban life, impermeable ground formation bound up with concretion is increasing day by day. Due to the impermeable floors, feeding of groundwater is prevented by rain water infiltrating into the soil and cause to be mixed into the rivers or sewage system by surface drainage of water. On the other hand, global climate change which has an important place on world agenda has triggered by urbanization, therefore temperatures increase to make urban heat island effect occur.

Starting from this point, this study was conducted in the case study of Tekirdağ to reveal the situation of the ground permeability in the urban fabric. In the study, current situation in terms of permeability of the ground was scrutinized by selecting a field hosting the different landscape structures in Tekirdağ city.

The results obtained in the impervious ground in the ratio of $57.5 \%$ were found to be considerably above the international criteria. This situation reveals that permeable grounds are not enough, thus providing not enough environmental contribution such as disposal of the urban heat island effect, providing hydrological watercycle, creating living space in the example of a micro-scale area in Tekirdağ urban fabric. In this matter, it has presented suggestions for improving the current situation.
\end{abstract}

Key Words: City, Urban landscape structure, Permeable grounds, İmpermeable grounds, Tekirdağ.

\section{Giriş}

Giderek hızlı bir ivme kazanan kentleşme sonucu günümüz kentleri; yeşil alanların giderek azalması, doğal drenajın ve su akışının değişmesi, buharlaşma yüzeylerinin yok olması vb. birçok sorunla karşı karşıya kalmıştır. Bu olumsuz durumlar iklimi, yerel ve bölgesel ölçekte etkileyerek değiştirmiş, ve kentlerimiz çevrelerinden bağımsız bir şekilde kendilerine özgü iklimlere sahip, termal konfor açısından sağlıksız alanlara dönüşmüştür (Sağlık ve ark., 2014; Duman 
Yüksel, 2008). Bu durum tarihte ilk kez İngiliz kimyager ve amatör meteorolog olan Luke Howard (1772-1864) tarafindan kentsel 1S1 adas1 etkisi olarak tanımlanarak literatüre girmiştir (Mills, 2007; URL1, 2016). Kentsel 1S1 adas1 etkisi kentleşme sonucunda sıcaklıklarda belirgin bir artışın meydana gelmesi ile kent ve çevresindeki kırsal alanlar arasında yüzey ve hava sicaklığında meydana gelen farklılık olarak tanımlanabilir (Çiçek ve Doğan, 2005).

Kentlerde 1s1 adası etkisi oluşturan bazı faktörler aşağıda verilmiştir (Barış, 2005; Kuşcu Şimşek ve Şengezer, 2012; Çiçek ve Doğan, 2005):

- Kentsel doku özellikleri ve bina kompozisyonları (binaların kanyon etkisi oluşturması), nüfus artışı ile yatay ve dikey yöndeki yapılaşma yoğunluğu, ulaşım gibi faktörler rüzgar hızı- yönü ve hava sıcaklığını etkilemektedir. Böylece kentin 1S1 dengesi değişmektedir.

- Kentsel alanlarda bitkilendirilmiş alanların azalması hava akımının ve buharlaşmanın azalmasına neden olarak 1siyı arttırmaktadır.

- Yol, bina vb. yüzey materyallerinde 1sınma kapasitesi ve 1s1 iletkenliği yüksek, geçirimsiz materyallerin kullanılması, koyu renkli yüzeylerin albedo (yansitabilirlik) etkisi yaratmas1 ile sicaklık artmaktadır. Geçirimsiz malzemeler yă̆ışın toprak altına geçerek yer altı sularını beslemesini engellemektedir.

- Sera gazları, yoğun enerji tüketimi, fosil yakıt kullanımı ve hava kirliliği sicaklıkları arttırmaktadır.

Dünya nüfusunun hızlı artışı ve gelişen teknoloji ile ortaya çıkan plansız ve çarpık kentler; geri dönüşümü olmayan, özellikle de hava, su, toprak gibi doğal kaynaklar ile ekolojik sistem üzerinde baskılar oluşturmaktadır (Yücel ve Morgil, 1998). Nitekim Tülek (2008)'in de ifade ettiği gibi günümüzde küresel boyutlara ulaşan bu çevre sorunlarının son dönemde hayatımıza en çok yansıyanlarından biri de, hiç şüphesiz su kaynaklarındaki hızlı kayıplardır. Bununla birlikte, küresel 1sınmanın getirdiği kuraklığın, özellikle ülkemiz gibi Akdeniz kuşağı ülkelerini etkileyeceği ve bu ülkelerin su yetersizliğine girerek kurak-yarı kurak zonda bulunacağı varsayımı tartışılmaktadır (Şahin, 2013). Keza, Özgüler (1997), yaptığ1 çalışmasında, artan su ihtiyacı ile giderek azalan temiz su kaynağı eğrilerinin 2030 yılında kesişeceğini gösterdiğini ve bu durumun evrensel bir krize neden olacağını ifade etmiştir (Akın ve Akın, 2007).

Kentleşmenin artması yağışlarda belirgin azalmalara neden olabilmektedir. Bu durum içme ve kullanma suyunda da azalmaya sebep olacaktır. Marmara Bölgesi için yapılan bazı çalışmalar büyük şehirlerin merkezlerinde yağışı gün sayısının azaldığını ortaya koymuştur. $\mathrm{Bu}$ durumun ortaya çıkmasında, bu şehirlerdeki çarpık şehirleşme ve hava kirliliği ile 1s1 adası oluşumunun diğer kentlere oranla daha fazla olmasının etkili olduğu saptanmıştır. (Kadıŏlu, 1997).

Çakıroğlu (2011), kentleşmenin hidroloji üzerine en büyük etkisinin ormanlar ve çayırlar gibi bitki örtüsünün, yol ve binalar gibi geçirimsiz yapilarla yer değiştirmesinden kaynaklandığının altını çizmektedir. Bununla birlikte, artan geçirimsiz yüzeyler yer altı suyunun beslenmesini engellemekte ve bu durum su korunumu açısından olumsuz sonuçlar doğurmaktadır. Oysa, geçirimli yüzeyler, yağış sularının yer altına sızmasına izin vererek yer altı sularını beslerken, aynı zamanda yüzeyde fazla su birikintileri oluşumunu da engellemektedir. Bu nedenle, çevre düzeninde geçirimsiz zeminler oluşturmaktan kaçınılmalıdır (Tıkansak, 2014). Bu bağlamda, yeşil alanlar; oksijen üretme, kirli havayı filtre ederek temiz hava temin etme, biyolojik çeşitliliği koruma, sera gazı etkilerini azaltma, erozyonu önleme, mikroklimatik etki kazandırma, iklimi ve su döngüsünü düzenleme gibi birçok konuda fayda sağlayan önemli unsurlardır (Önder ve Polat, 2012; Çakıroğlu, 2011).

Günümüzde kentsel su verimliği kapsamında su kullanımı ve yönetimi ile ilgili geleneksel ve sürdürülebilir sistemler geliştirilmiştir (Ekinci, 2015). Ancak, peyzaj karakterine dayalı analiz ve değerlendirme süreçleri uygulamada yerini alamadığından, peyzajlar tahrip olmaya ve doğal kaynaklar 
geri dönüşümü olmayan bir şekilde yok olmaya devam etmektedir (Çakıroğlu, 2011).

Yukarıda değinilen tüm bu hususlar günümüz kentlerinin karşı karşıya kaldığı bu sorunların, doğal kaynakların sürdürülebilirliği ve yönetimi açısından doğaya saygıl1, ekolojik birtakım yaklaşımlarla çözümlenmesinin gerekliliğini ortaya çıkarmaktadır. $\mathrm{Bu}$ doğrultuda çalışmada kentsel peyzaj yapılarını içeren bir alan pilot bölge olarak belirlenerek buradaki geçirimli-geçirimsiz zeminler saptanmış ve böylece "parçadan bütüne ulaşmak" görüşü ile kentin bütünü için yorum getirebilmek amaçlanmıştır. Çalışmada kentsel peyzaj planlama ve tasarımlarına yönelik ekoloji duyarlı çözüm önerileri geliştirilmiştir. Nitekim, kentsel peyzaj planlamada ekolojik temelli planlama yaklaşımları geliştirebilmek için ise kent ekolojisi ve kent ekosistemini bilmek, doğru planlama ve tasarım kararları almak açısından önemli bir adım taş1 olacaktır. Bu bağlamda aşağıda kent ekolojisi ve kentsel peyzajın yapısını oluşturan unsurlar ortaya konulmuştur.

\section{Kentsel peyzajı oluşturan yapılar}

Kentler; doğal ve kültürel birçok unsurun etkileşimi ile oluşmuş insan ekosistemleridir (Karadağ, 2009). Bir kent ekosistemi yapılar ve onları çevreleyen alanlardan meydana gelir. Cadenasso ve Pickett (2008)'e göre ekosistem kavramı için tek bir mekansal ölçek söz konusu değildir. Kentin tamamı bir ekosistem olabilirken, bir havza, kent içindeki bir mahalle veya bir parsel de ekosistem olabilir. Küçük ekosistemler fiziksel olarak daha geniş ekosistemler içinde yer alırlar. $\mathrm{Bu}$ hiyerarşik düşünce yapısı peyzaj tasarımlarında ekolojik anlayıșın uygulanmasina olanak verir. Kent ekolojisi heterojen bir yapıya sahip olup, kentsel peyzajın heterojen yapısı üç yapısal eleman ile tanımlanır. Bunlar: yapılar (örn. yerleşim ve endüstri alanları), bitki örtüsü (örn. kent ormanı) ve yüzeylerdir (örn. geçirimsiz kaplamalı alanlar ve toprak yüzeyler) (Çetinkaya ve Uzun, 2014). Peyzaj ekolojisinin analiz edilmesinde ise yeryüzü mozaiğini oluşturan leke koridor-matris modeli başlıca unsurlardan biridir (Çabuk ve ark., 2012). Bu bağlamda leke-koridor ve matrisi tanımlayacak olursak:

Leke: Forman ve Godron (1986) lekeyi, büyüklük, şekil, tip, heterojenlik ve sınır özellikleri bakımından oldukça farklılık gösteren doğrusal olmayan yüzey alanı olarak tarif etmektedir. Genellikle, değişik tür yapıs1 ya da kompozisyonuna sahip olan ve kendilerini çevreleyen matrisin içine gömülüdürler (Gökyer, 2009).

Koridor: McGarigal ve Marks (1995) koridorları; doğrusal peyzaj öğeleri olarak tanımlamaktadır. Yapı ve fonksiyonu esas alan koridorlar, sahip oldukları doğrusal yapılarından dolayı lekelerden farklılık göstermektedirler. Bu yönleri sayesinde hem yapısal hem işlevsel hem de her iki özelliği bir arada barındırırlar (Sütünç, 2012).

Matris: Forman ve Godron (1986) matrisi, bir peyzajın, tipik olarak bir kaç peyzaj ögesinin (örn. lekeler) bir araya gelmesi ile oluştuğunu ifade etmiştir (Sütünç, 2012). Odum ve Barrett (2008)'e göre matris peyzajın ana iskeletini oluşturur ve leke ve koridorlar bu iskelet üzerinde yer alır (Çetinkaya ve Uzun, 2014). Matrislerle lekeleri ayırt etmede iki önemli faktör boyut ve diş şekildir. Matris, toplam alan içinde çok daha geniş olup; diğer peyzaj elemanlarını kuşatan iç bükey sinırlara sahiptir (Gökyer, 2009).

Tablo 1'de kentsel peyzajin yapisinı oluşturan başlica leke-koridor-matris unsurları verilmiştir.

Tablo 1. Ahern (1997)'e göre kentsel peyzajın yapısını oluşturan başlıca leke-koridor-matris unsurları (Çetinkaya ve Uzun, 2014)

\begin{tabular}{lll}
\hline Kentsel lekeler & Kentsel koridorlar & Kent matrisi \\
\hline Parklar & Akarsular & Yerleşim alanları \\
Spor alanları & Kanallar & Endüstriyel alanlar \\
Sulak alanlar & Akarsular boyunca doğrusal yeşil alanlar & Ticari merkezler \\
Ev bahçeleri & Yollar & Altyapi \\
Mezarlıklar & Yol kenarı ağaçlandırması & \\
Kampüsler & Tarım alanları çevresinde doğrusal olarak uzanan yeşil & \\
& alanlar & \\
\hline
\end{tabular}




\section{Materyal ve Metot}

$\mathrm{Bu}$ çalışma, Tekirdağ ili Süleymanpaşa ilçesinde seçilen bir alanda yürütülmüsstür. Tekirdağ, Türkiye'nin kuzeybatısında, Marmara Denizi'nin kuzeyinde, tamamı Trakya topraklarında yer alan üç ilden biri, ayrıca Türkiye'de iki denize kıyısı olan altı ilden biridir. Tekirdağ $40^{\circ} 36^{\prime}$ ve $41^{\circ} 31^{\prime}$ kuzey enlemleri ile $26^{\circ} 43^{\prime}$ ve $28^{\circ} 08^{\prime}$ doğu boylamları arasında yer almaktadır. Yüzölçümü $6.313 \mathrm{~km}^{2}$ olan kentin denizden yüksekliği 0-200 m arasındadır. İl, doğudan İstanbul'un Silivri ve Çatalca, kuzeyden Kırklareli'nin Vize, Lüleburgaz, Babaeski ve Pehlivanköy, güneyden Marmara Denizi ve Çanakkale'nin Gelibolu ilçesi ile çevrilidir. Tekirdağ'ın güney sınırı boyunca uzanan Marmara Denizi'nde 133 km kıyss1, kuzeydoğudan Karadeniz'e 2,5 km kiyısı vardır (URL2, 2012).

Tekirdağ, genel nemlilik indislerine göre bulunan hidrografik bölgelerden yarı nemli iklim tipi içine girmektedir. Yağı̧̧ rejimi bakımından Akdeniz yağış rejimi kategorisinde bulunmaktadır. Tekirdağ sahil şeridinde Akdeniz ikliminin etkileri görülürken Ergene havzasını içine alan kıyı şeridi ardında kara iklimi hakimdir. Tekirdağ'da ortalama olarak en az yağış Ağustos, en fazla Aralık aylarında görülür. Yaz ve kış mevsimleri oldukça rüzgarlıdır. Hakim ve sürekli rüzgar poyraz, ikinci etkin rüzgar lodostur (URL3, 2016). Meteoroloji Genel Müdürlüğü'nün uzun yıllar içinde (1950-2015) gerçekleşen ortalama istatistikî değerleri dikkate alındığında, Ağustos ayı en yüksek $\left(28,1^{\circ} \mathrm{C}\right)$ sıcaklığa sahipken, Ocak ayı en düşük $\left(2,1{ }^{\circ} \mathrm{C}\right)$ sicaklığa sahiptir. Ortalama güneşlenme süresi en fazla Haziran, en az Aralık aylarında görülür. Ortalama yağışlı günler ise en çok Ocak, en az Ağustos aylarında olmaktadır (URL4, 2016). Tablo 2'de Tekirdağ iline ait ortalama meteoroloji değerleri verilmiştir (Tablo 2).

Tablo 2. Tekirdağ iline ait uzun yıllar içinde gerçekleşen ortalama meteorolojik değerler $(1950$ - 2015)

\begin{tabular}{|c|c|c|c|c|c|c|c|c|c|c|c|c|}
\hline Türkiye & ङँ & $\underset{\Xi}{\Xi}$ & $\stackrel{\Sigma}{\Sigma}$ & 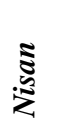 & 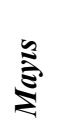 & $\begin{array}{l}\mathbb{Z} \\
\mathbb{Z} \\
\mathbb{Z}\end{array}$ & 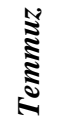 & 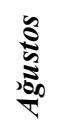 & $\underset{\mathbf{D}}{\stackrel{\Xi}{\$}}$ & 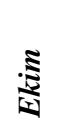 & 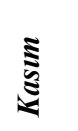 & $\underset{⿱ 亠 乂}{\Xi}$ \\
\hline Ortalama Sicaklık $\left({ }^{\circ} \mathrm{C}\right)$ & 4.9 & 5.4 & 7.4 & 11.9 & 16.9 & 21.3 & 23.8 & 23.8 & 20.0 & 15.4 & 11.0 & 7.2 \\
\hline $\begin{array}{l}\text { Ortalama En Yüksek } \\
\text { Sicaklık }\left({ }^{\circ} \mathrm{C}\right)\end{array}$ & 8.2 & 8.9 & 11.0 & 15.8 & 20.6 & 25.3 & 28.0 & 28.1 & 24.4 & 19.6 & 14.7 & 10.5 \\
\hline $\begin{array}{l}\text { Ortalama En Düşük } \\
\text { Sicaklık }\left({ }^{\circ} \mathrm{C}\right)\end{array}$ & 2.1 & 2.4 & 4.1 & 8.2 & 12.6 & 16.6 & 18.9 & 19.3 & 16.0 & 12.0 & 8.0 & 4.4 \\
\hline $\begin{array}{l}\text { Ortalama Güneşlenme } \\
\text { Süresi (saat) }\end{array}$ & 2.4 & 3.2 & 4.1 & 5.4 & 7.4 & 9.6 & 9.5 & 9.0 & 7.2 & 4.5 & 3.2 & 2.3 \\
\hline $\begin{array}{l}\text { Ortalama Yağışlı Gün } \\
\text { Sayısı }\end{array}$ & 12.4 & 10.8 & 10.7 & 9.8 & 8.2 & 7.2 & 3.6 & 2.5 & 4.8 & 7.6 & 9.6 & 11.9 \\
\hline $\begin{array}{l}\text { Aylık Toplam Yağış } \\
\text { Miktarı Ortalaması }(\mathrm{kg} / \mathrm{m} 2)\end{array}$ & 69.0 & 54.1 & 54.9 & 41.3 & 38.5 & 37.7 & 23.2 & 14.0 & 36.3 & 64.3 & 74.6 & 81.2 \\
\hline
\end{tabular}

Çalıșma alanının belirlenmesinde; alanın İstanbul - Tekirdağ ana ulaşım güzergahı üzerinde olması, kente giriş sağlayan ve kentin imgesini belirleyebilecek nitelikte bir koridor olması, kent merkezine ulaşımda tek alternatif olması ve gelişmekte olan yerleşim dokusu içinde yer alması etkili olmuştur (Şekil 1). Tekirdağ ili Süleymanpaşa ilçesine bağl1 mahalleler, toplamda 5.520 hektarlık alanı kaplamaktadır. Çalışma alanının da içinde yer aldığ1 Hürriyet Mahallesi ise yaklaşık 315 hektar alana sahiptir. 


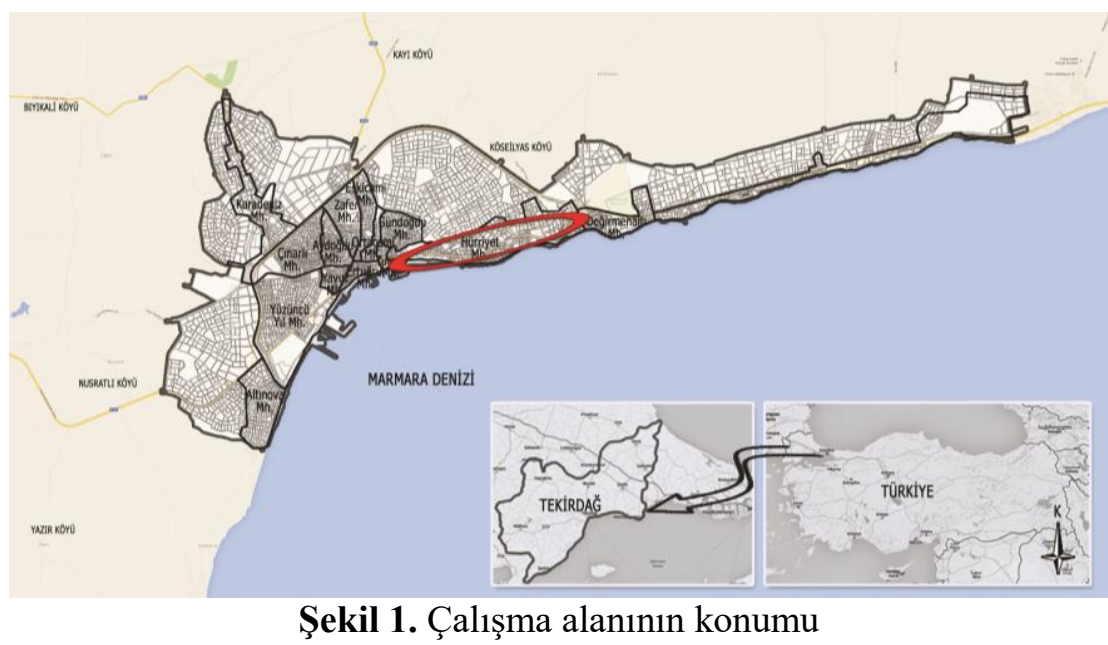

Çalıșma alanının sınırlarını; Süleymanpaşa İlçesi Hürriyet Mahallesine bağlı Fatih Sultan Mehmet Bulvarı ile bu bulvara paralel olan, 100 metre genişlik ve 4.835 metre uzunluktaki ulaşım ağ1 oluşturmaktadır. Bu ulaşım ağı kuzeyden 50 metre, güneyden 50 metre olmak üzere farkl1 kullanım alanlarını içermekte ve yaklaşık 47 hektar alan kaplamaktadır.

Çalışma için, öncelikle Tekirdağ Büyükşehir Belediyesi’nden 1/25000 ölçekli imar planı temin edilmiştir. Ayrıca Tekirdağ'a ilişkin uydu görüntülerinden yararlanılmıştır. Çalışma alanındaki peyzaj yapılarını oluşturan leke, koridor ve matrisler ile geçirimli ve geçirimsiz zeminlerin belirlenmesinde imar planları ile Google Earth 2015 uydu görüntüleri çakıştırılmıştır.

Çalışma kapsamında, uluslararası benzer çalışmalarda da kullanılan kriterlerden yararlanılarak çalışma alanındaki yumuşak/sert zeminlerin geçirimlilik bakımından sahip olması gereken oranlar belirlenmiştir. Çalışma alanı sınırları içindeki geçirimli ve geçirimsiz zeminler Google Earth 2015 uydu görüntüsü ile belirlenmiştir ve alanının peyzaj yapısının analizinde kullanılmıştır.

Çalışmanın iş-akış diyagramı Şekil 2'de verilmiştir.

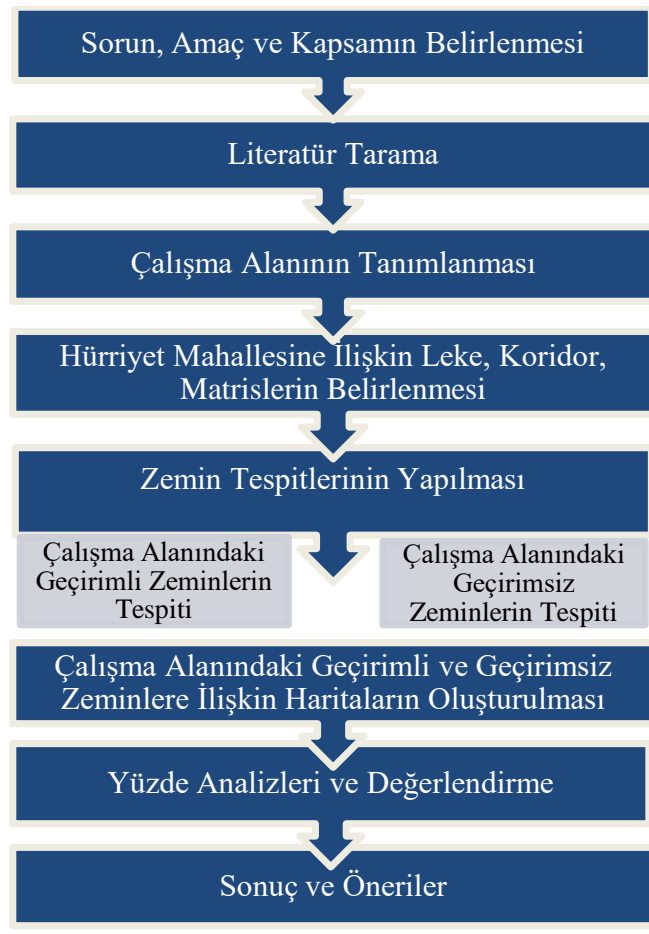

Şekil 2. Çalışmanın iş-akış diyagramı

\section{Bulgular ve Tartışma}

Süleymanpaşa İlçesi, kentsel peyzaj yapıları bakımından çeşitlilik göstermektedir. İlçe merkezi yerleşim matrisini, komşu parseller tarım matrisini, bu matrisleri birbirlerine bağlayan Fatih Sultan Mehmet Bulvarı ile yollar ise koridorları oluşturmaktadır. Kent içerisinde nüfus ve alan kullanımına göre genel ihtiyacı karşılaması bakımından yetersiz olan yeşil alanlar ise lekeler halinde bulunmaktadır (Şekil 3). 


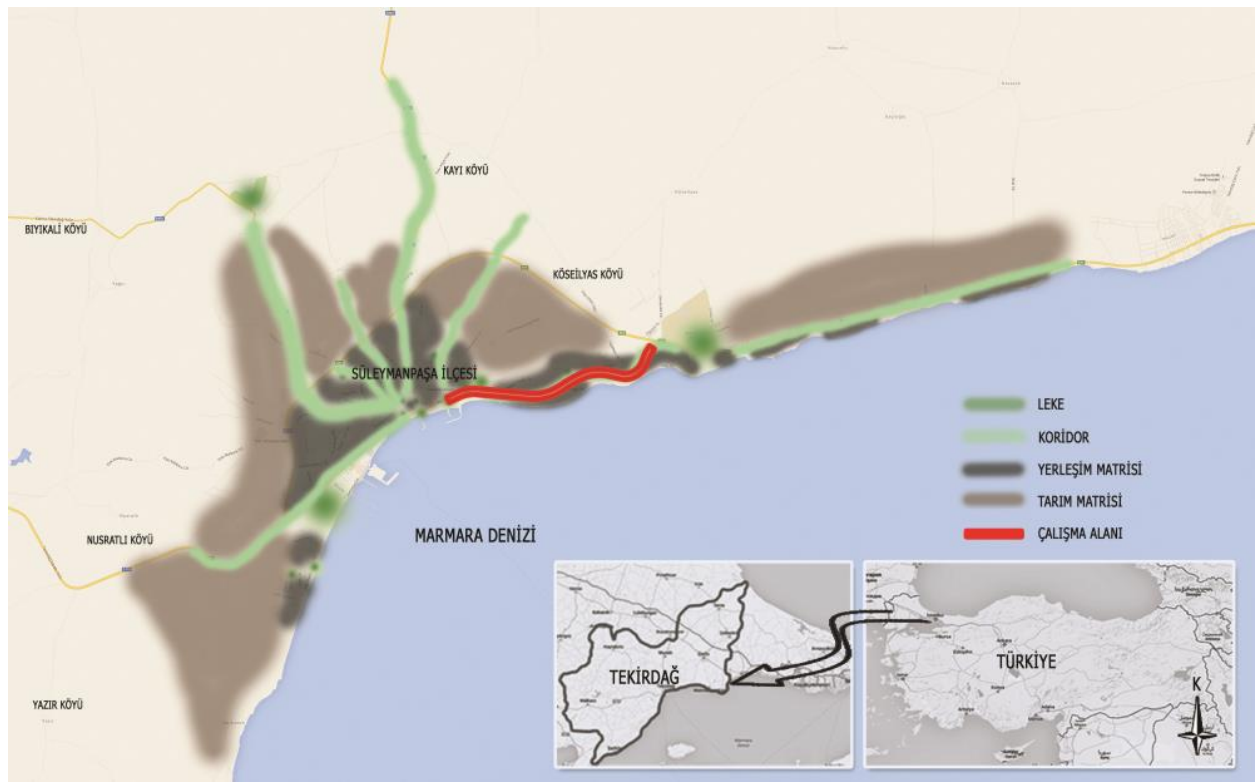

Şekil 3. Süleymanpaşa İlçesi’ndeki peyzaj yapılarının dağılımı

Araştırmadan elde edilen verilere göre; çalışma alanı sınırları içerisinde de, kentsel peyzaj yapılarından her üçüne ait leke, koridor ve matrisler bulunmaktadır. Çalışma alanı içerisine giren peyzaj yapılarının daha detaylı görünümü Şekil 4'te verilmiştir.

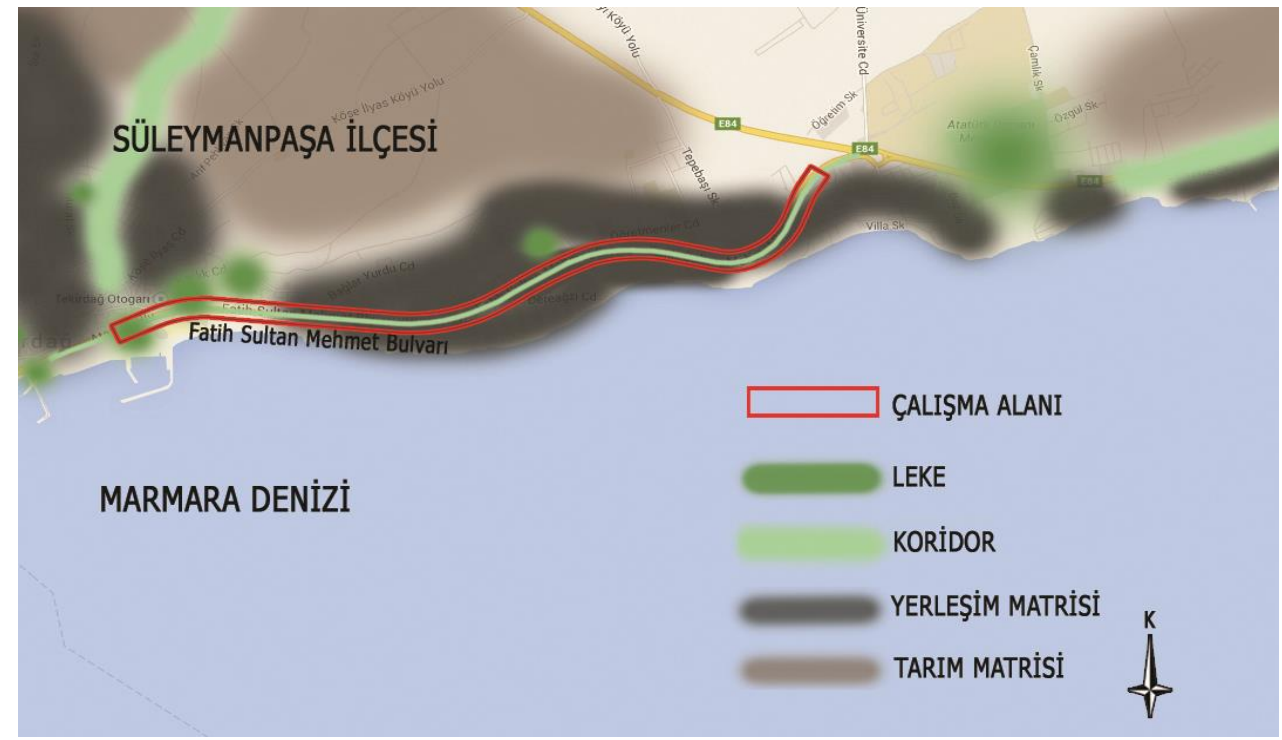

Şekil 4. Çalışma alanı içerisine giren peyzaj yapıları

Ahern 1997'e göre parklar, peyzaj yapısını oluşturan lekelerdir (Çetinkaya ve Uzun, 2014). Hürriyet Mahallesi Belediye Meclisi'nde alınan karara göre, son yıllarda düzenlenen yeni açık alanlarla birlikte 12 adet park bulunmaktadır (Tablo 3). Bu parklardan Barış ve Özgürlük Parkı, Belediye Başkanı Hüsnübey Parkı, Mikes Kelemen Parkı ve Mola Parkının bir bölümü çalışma alanı sınırlarına girmektedir. 
Tablo 3. Süleymanpaşa ilçesinde bulunan parklar ve mahallelere göre dağılımı (Şişman ve Gültürk 2014'ten geliştirilerek)

\begin{tabular}{lll}
\hline Mahalle & Parkın Adl & Büyüklük $\left.\boldsymbol{( m}^{2}\right)$ \\
\hline Hürriyet Mahallesi & Mola Park* & $\mathbf{9 6 2 6}$ \\
& Kent Park & 4370 \\
& Bahar Park1 & 1700 \\
& Oba Park & 357 \\
& Süleyman Paşa Park1 & 1745 \\
& Fatih Sultan Mehmet Park1 & 2361 \\
& Tredaş Önü Park1 & 5757 \\
& Barış ve Özgürlük Parkı* & $\mathbf{1 5 3 1 4}$ \\
& Yavuz Sultan Selim Park1 & 1871 \\
& Kanuni Sultan Süleyman Park1 & 1263 \\
& Belediye Başkanı Adilbey Parkı & 4000 \\
& Belediye Başkanı Hüsnübey Parkı* & $\mathbf{1 0 9 7}$ \\
& MikesKelemen Parkı* & $\mathbf{5 5 0}$ \\
Toplam & $\mathbf{5 0 0 1 1}$ \\
\hline
\end{tabular}

* işaretli olan parklar çalışma alanı sınırlarına giren parkları göstermektedir.

Çalışma alanına giren parsellerin geçirimli ve geçirimsiz zemin oranlarının belirlenmesinde; Doygun ve Kisakürek (2013)'te verilen yöntem dikkate alınmıştır. Buna göre; yüzey sularının kolaylıkla drene olabilmesine izin veren çim, çalı, ağaç vb. bitki örtüsüyle ve toprakla kaplı zeminler geçirimli; yap1, beton, asfalt, kilit parke vb. sert materyallerle kapli zeminler ise geçirimsiz zemin olarak değerlendirilmiştir. $\mathrm{Bu}$ zeminlerin bütün çalışma alanına oranları Tablo 4' te verilmiştir.

Tablo 4. Çalışma alanındaki geçirimli ve geçirimsiz zemin oranları

\begin{tabular}{clcc}
\hline & \multicolumn{1}{c}{ Alan tipi } & $\boldsymbol{m}^{2}$ & \% \\
\hline \multirow{2}{*}{ Geçirimli } & Düzenlenmemiş ve düzenlenmiş açık alanlar & 199553 & 42.5 \\
& Geçirimli zemin toplam alanı & $\mathbf{1 9 9 5 5 3}$ & $\mathbf{4 2 . 5}$ \\
Geçirimsiz & 169323 & 36.1 \\
& Yollar ve kaldırımlar & 54604 & 11.6 \\
& Yapılar & 46338 & 9.8 \\
& Sert zeminli konut parselleri & $\mathbf{2 7 0 2 6 5}$ & $\mathbf{5 7 . 5}$ \\
& Geçirimsiz zemin toplam alanı & $\mathbf{1 0 0}$ \\
\hline
\end{tabular}

Tablo 4'te görüldüğü gibi toplam $469.818 \mathrm{~m}^{2}$ bir alan kaplayan çalışma alanının \% 42.5'i suyun drenajına imkan veren geçirimli zeminlerden oluşmakta iken, \% 57.5' $\mathrm{i}$ ise yollar, kaldırımlar, yapılar ve sert zeminli konut parselleri nedeniyle geçirimsiz zemine sahiptir. Geçirimsiz zeminler de suyun yüzey akışları ile kaybına neden olmaktadır. Geçirimli ve geçirimsiz zeminlere ilişkin oluşturulan haritalar Şekil 5'te görülmektedir. Yüzey kaplamaları ile oluşturulan mekanların zemin geçirgenlik oranlarının değerlendirilmesinde, Anonymous (2004)'a göre kullanılan uluslararası kriterler dikkate alınmıştır (Doygun ve Kısakürek, 2013). Bu kriterlere göre; sert zeminle kaplı alanların bütün içerisindeki oranı \%20'den büyük ise, bu mekanın geçirgenlik düzeyinin ekolojik bakımdan "uygun olmadığı" şeklinde değerlendirilmiştir. \%10-20 arasındaki sert zemin oranı ise yoğun olarak kullanılan yeşil alanlar için ekolojik bakımdan "kabul edilebilir" iken, \%5-10 arasındaki sert zemin oranı yeşil alanların geneli için "iyi", \%5'ten küçük sert zemin oranı ise "ideal" kabul edilmektedir. 


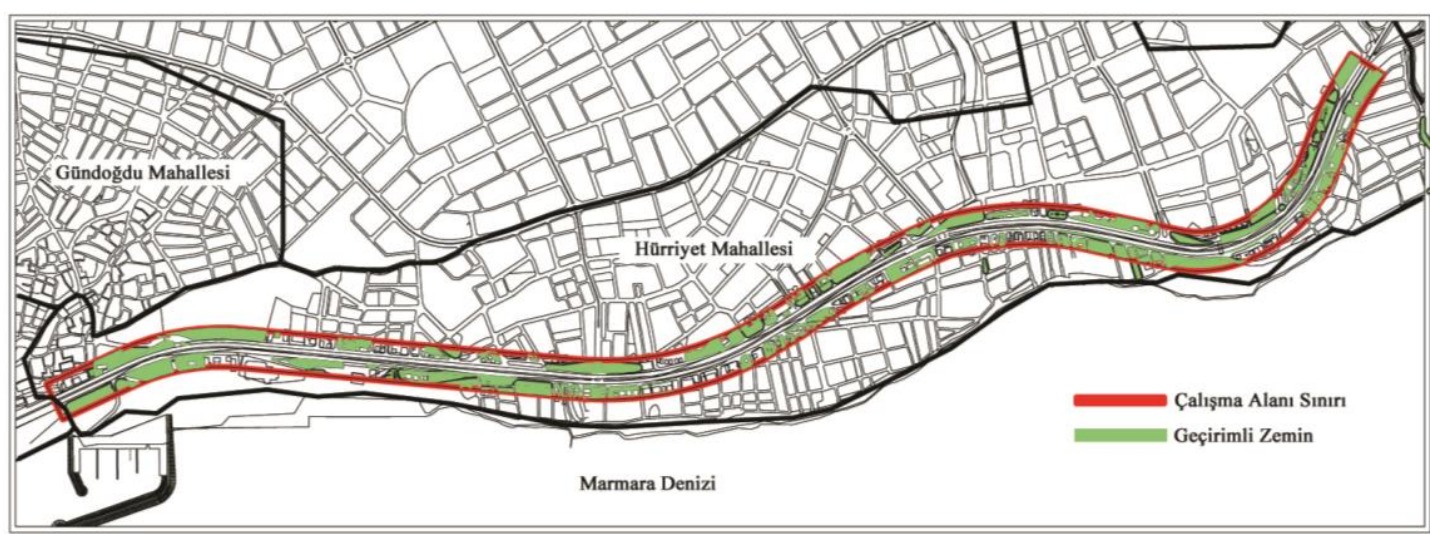

(a)

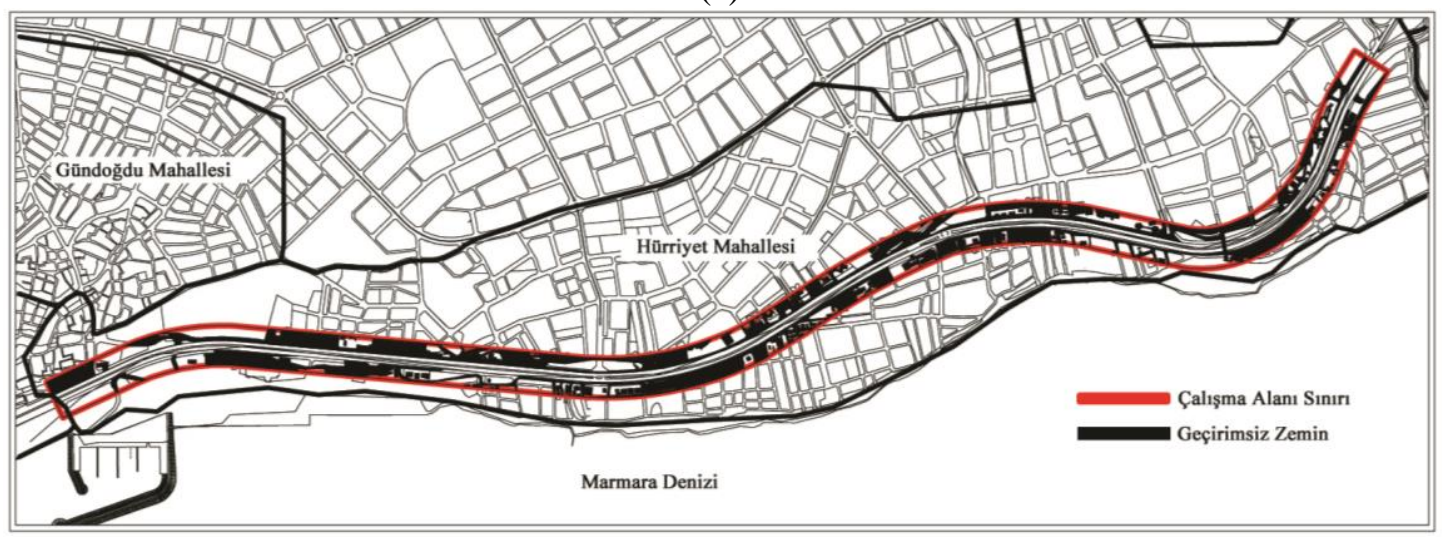

(b)

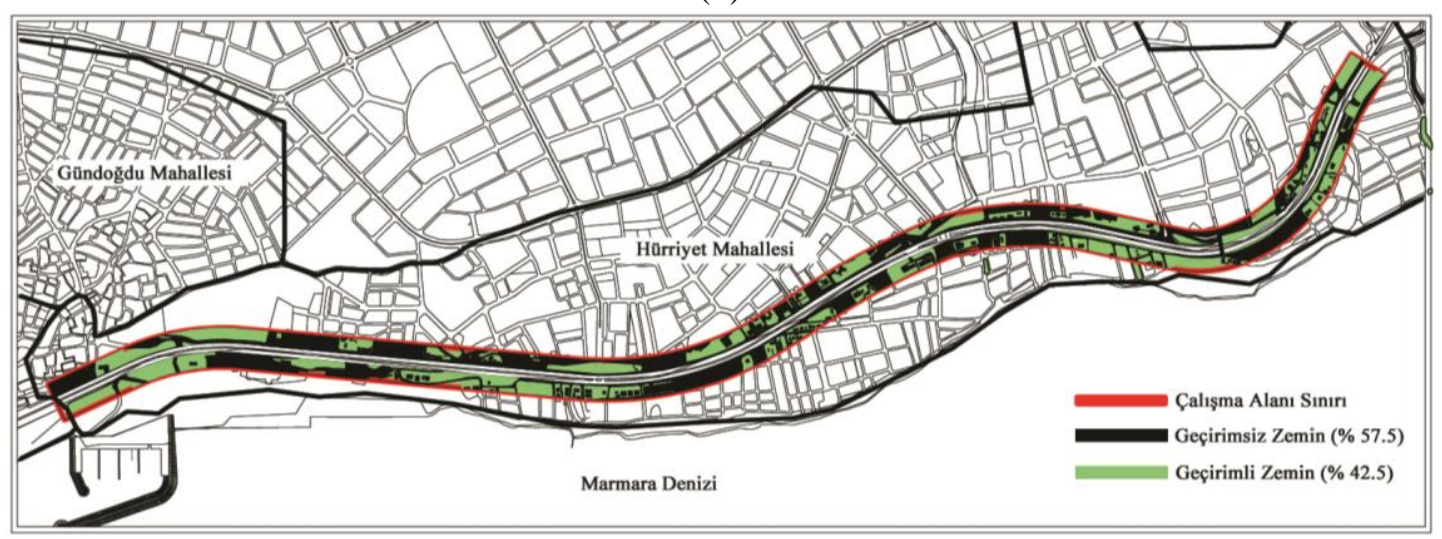

(c)

Şekil 5. (a) Çalışma alanına ilişkin geçirimli zeminler haritası, (b) Çalışma alanına ilişkin geçirimsiz zeminler haritası ve (c) Çalışma alanındaki geçirimli ve geçirimsiz zeminler haritası (yüzde değerleri ile) (Orj.)

Nitekim, Eşbah (2006) kent parklarındaki yüzey geçirimliliklerini irdelediği çalışmasında; bir parkta geçirimli yüzeylerin oranı ne kadar yüksek ise, ekolojik dengesinin de o kadar yüksek varsayıldığını, o parkın biyolojik aktiviteye, materyal ve enerji alışverişine o kadar çok imkan tanıdığını belirtmiştir. Yine aynı araştırıcı, bunun tersi durumlarda ise, ekolojik kalitenin düşüklük gösterdiğini ve böyle alanların hem yaban hayatı hem de kente sağlayacağı ekolojik faydaların da düşük olacağına işaret etmiştir.

$\mathrm{Bu}$ bağlamda, araştırma bulguları söz konusu kriterler bakımından değerlendirildiğinde, \%57.5 geçirimsiz zemin oranının minimum kriter olan $\% 20$ oranının çok üzerinde olduğu ve bu durumun 
ekolojik açıdan uygun olmadığ görülmektedir. Geçirimli zemin olarak ise, $\%$ 42.5 oranında bir tespit yapılmış olup, bu oranın \%51.6'sını oluşturan $102831 \mathrm{~m}^{2}$ 'lik kısmı imar planında park veya refüj olarak belirlenmiştir. Bunun dişında kalan alanlar ise özel mülkiyete ait konut parselleridir.

$\mathrm{Bu}$ verilerin, ilçenin yaşam kalitesi bakımından en iyi durumda olan mahallesinden bir kesiti yansıttığ düşünülürse, ilçenin diğer mahallelerinde geçirimli zemin oranının çok daha düşük çıkması kuvvetle muhtemel olacaktır.

\section{Sonuç}

Hizlı ve sağlıksız kentsel gelişim, kentlerdeki beton, asfalt, cam yüzeyleri dolayisıyla sert zeminleri artırmakta, yeşil alanların azalmasına ve sonuçta geçirimli yüzeylerin giderek kaybolmasina neden olmaktadır. $\mathrm{Bu}$ durum kentsel yerleşim alanlarındaki yeraltı su kaynaklarını tehdit etmekte, iklim değişiklerinin kentlerde çok daha etkili olmasına yol açmaktadır. Giderek daha fazla insan yoğunluğuna maruz kalarak betonlaşan, geçirimsiz zeminleri artan ve yeşil alanları azalan kentlerde hissedilebilir sıcaklıklar artmakta, yağış suları yüzey akışlarıyla kaybolmakta kentsel 1S1 adası etkisi ortaya çıkmaktadır.

Araştırma sonucunda ortaya çıkan \%57.5 değerindeki geçirimsiz zemin oranının uluslararası kriterler bakımından minimum kriter olan \%20 oranının çok üzerinde olduğu ve bu durumun ekolojik açıdan uygun olmadığı belirlenmiştir. Nitekim, Şekil 3'te "Süleymanpaşa ilçesindeki peyzaj yapılarının dağılımı" haritasında verilmiş olan diğer leke ve koridorlarda da bu yönde benzer sorunların ortaya çıması muhtemeldir. Örnek seçilen alanın üç farklı kentsel peyzaj yapısını içerdiği dikkate alınırsa; "parçadan bütüne ulaşmak" görüşü doğrultusunda bu sonuç, kent genelinde geçirimsiz zeminler konusunda bir fikir vermektedir. Diğer taraftan, araştırma alanının dahil olduğu Hürriyet Mahallesi; yaşam kalitesi sosyal, ekonomik, kültürel ve çevre açısından diğer mahallelere göre daha olumlu özellikler taşımaktadır. $\mathrm{Bu}$ durum da dikkate alındığında, \%57.5 değerindeki geçirimsiz oranın kentin diğer mahallelerinde daha da yüksek oranlarda olacağı, diğer bir ifade ile zemin geçirgenliği uluslararası kriterlerinin minimum değeri olan \%20'nin 4-5 katına ulaşabileceği kuvvetle muhtemeldir.

Buradan yola çıkılarak Tekirdağ örneğinde, kent dokusunda farklı amaçlarla kullanılan zeminlere yönelik alınabilecek önlemler aşağıdaki gibi özetlenebilir:

- Kent dokusunda zorunlu sert zeminler dışındaki zeminlerin mümkün olduğunca geçirimli zeminler olmasına özen gösterilmelidir. Örneğin otopark zeminlerinde geçirimsiz taş, asfalt beton vb. yerine çim derzli taşlar ya da adım taşları gibi geçirimliliği olan zemin kaplamaları tercih edilmelidir.

- Zeminlerde 1s1 emilimi düşük yüzey kaplamalarının kullanılması gerek biyo konfor gerekse enerji etkin peyzaj tasarımları açısından tercih edilmelidir. Ayrıca zemin kaplama malzemelerinde, malzeme renginin soğurma etkisi de dikkate alınmalıdır.

- Taş, beton, tuğla gibi zemin malzemelerinin kullanılmasının gerekli olmadığı durumlarda sadece kırmızı toprak kullanımı ile doğal bir zemin oluşturulması yoluna gidilmelidir. Özellikle bu hususa kamusal park ve bahçelerde dikkat edilmelidir.

- Yüzey sularının toprak altına sızarak yeraltı su kaynaklarını beslemesi için geçirimli yüzeylerdeki toprak tabakalarının sıkışmasını ve nem kaybını önlemeye yönelik önlemler alınmalıdır. Keza Çakıroğlu (2011)'nun da ifade ettiği gibi dünyada yağış suyu yönetim planları kapsamında geliştirilen su hasadı, su tutma bahçeleri, yağmur bahçeleri gibi özel uygulamalar bulunmaktadır. $\mathrm{Bu}$ tür uygulamalar kentsel yeşil alan sisteminin bileşenleri olarak kentsel peyzaj tasarımlarında yer almalıdır.

- Kaldırım gibi sert zeminlerin içinde çukur açılarak ağaç dikimi yapmak yerine, araç yolu ile yaya yolları arasında yeşilin sürekliliğini sağlayacak yeşil bir şerit oluşturulması ile suyun toprak altına inmesine olanak sağlanmalıdır.

- Yeşil şeritlere hem yüzeysel hem de derin kök sistemine sahip bitkilerin dikilmesi tercih edilmelidir.

Çalışmada ele alınan bu koridordaki sorunun çözümü elbetteki kent bütünü için yeterli olmayacaktır. $\mathrm{Bu}$ bağlamda 
"bütünsel" yaklaşımlar ele alınmalıdır. Bu noktada leke ve koridorlardaki yapisal ve işlevsel değişimler ve bozulmalara karşı yeşil yol, yeşil altyap1, yeşil ağ gibi bütünsel yaklaşımlar bilhassa değerlendirilmelidir. Özellikle sürdürülebilir kentler için yeşil alt yap1 planları büyük bir ihtiyaçtır. Kentsel yaşamda karşı karşıya kaldığımız çok sayıda olumsuz etkiyi tamamen ortadan kaldırmak mümkün olmasa da, uygulamaya konulabilecek önlemlerle kent dokusunda olumlu yönde değişiklikler meydana gelecektir. Geçirimli malzeme kullanımı ve yararlarına yönelik özellikle yerel yönetimlerde farkındalık ve bilinç oluşturulması da önemlidir.

\section{Kaynaklar}

Ahern J. 1997. At the crossroads: Sustainable future or urban sprawl? Spatial concepts and scenarios fort he lisbon metropolitan area. Environmental challenges in an urban world and the role of emerging information technologies conference, Lisbon, Portugal.

Akın M., Akın G. 2007. Suyun önemi, Türkiye'de su potansiyeli, su havzaları ve su kirliliği. Ankara Üniversitesi Dil ve TarihCoğrafya Fakültesi Dergisi. 47(2), 105-118.

Anonymous, 2004. Making greener cities: a practical guide. Development of Urban Green Spaces to Improve the Quality of Life in Cities and Urban Regions. Research Project, UZF Center for Environmental Research.

Barış E. 2005. Kent planlaması, kent ekosistemi ve ağaçlar. Planlama 2005/4,TMMOB Peyzaj Mimarları Odası Ankara, 156-163.

Cadenasso M.L., Pickett S.T.A. 2008. Urban principles for ecological landscape design and management: scientific fundamentals. Cities and the Environment, 1 (2), 1-16.

Çakıroğlu G. 2011. Peyzaj tasarımında su tasarrufuna yönelik güncel uygulamaların irdelenmesi: İstanbul örneği. Yüksek Lisans Tezi, İÜ Fen Bilimleri Enstitüsü, 188 s. İstanbul.

Çetinkaya G.,Uzun O. 2014. Peyzaj Planlama. 4. Bölüm (Peyzaj Planlama Süreci) Birsen Yayınevi, Yayın No: 0029, 101-102, İstanbul.

Çabuk S.N., Ersoy M., Çabuk A., Hocaoğlu T., Bakış R. 2012. Su kaynaklarının planlanmasında coğrafi bilgi teknolojileri kullanımı ve geotasarım kuramı. FABA 2012 Sempozyumu (21-24 Kasım 2012), Eskişehir, Türkiye.

Çiçek İ., Doğan U. 2005.Ankara'da şehir 1S1 adasının incelenmesi.Coğrafi Bilimler Dergisi,3 (1), 57-72.
Doygun N.,Kısakürek Ş. 2013. Kahramanmaraş'ta bazı kent parklarının geçirimli zemin yeterliği bakımından incelenmesi. İnönü Üniversitesi Sanat ve Tasarım Dergisi, 3(7), 2329.

Duman Yüksel Ü. 2008. Kentlerde yapısal ve yeşil alanlardaki hava ve yüzey sıcaklıklarının irdelenmesi: Ankara örneği. Ekoloji, 18 (69), 6674.

Ekinci B. 2015. Su kaynaklarının verimli kullanılmasına yönelik örnek ülke uygulamaları ve ülkemizde bu çalışmaların uygulanabilirliği. Uzmanlık Tezi. T.C. Orman ve Su İşleri Bakanlı̆̆ı, 134 s. Ankara.

Eşbah H. 2006. Aydın'da kent parklarının bazı ekolojik kalite kriterleri yönünden irdelenmesi. Ekoloji, 15 (58), 42-48.

Forman R.T.T., Godron M. 1986. Landscape ecology. John Wiley \& Sons, pp. 620, New York.

Gökyer E. 2009. Bartın kenti ve Arıt Havzası'nda peyzaj değerlendirme. Doktora Tezi, AÜ Fen Bilimleri Enstitüsü, 143 s. Ankara.

Kadıŏlu M. 1997. Şehirleşmenin Marmara Bölgesindeki yağışlara etkisi. Su ve Çevre Sempozyumu (2-5 Haziran 1997), İstanbul, Türkiye.

Karadağ A. 2009. Kentsel ekoloji: kentsel çevre analizlerinde coğrafi yaklaşım. Ege Coğrafya Dergisi, 18(1-2), 31-47.

Kuş̧̧u Şimşek Ç., Şengezer B. 2012. İstanbul metropoliten alanında kentsel 1sınmanın azaltılmasında yeşil alanların önemi. Megaron 7(2), 116-128.

Mc Garigal K., Marks B. J. 1995. Fragstats: Spatial pattern analysis program for quantifying landscape structure. Gen. Tech. Rep. PNG-GTR351. Portland, OP: U.S. Department of Agriculture, Forest Service, Pacific Northwest Research Station. pp 122.

Mills G. 2007. Luke Howard and the climate of London. Weather 63, pp. 153-157.

Odum E.P., Barrett G.W. 2008. Ekolojinin temel ilkeleri. Çeviri editörü: Prof. Dr. Kani IȘIK, Beşinci baskıdan çeviri. ISBN: 978-9944-341-745. Palme Yayınları. Ankara.

Önder S., Polat A.T. 2012. Kentsel açık-yeşil alanların kent yaşamındaki yeri ve önemi. Kentsel Peyzaj Alanlarının Oluşumu ve Bakım Esasları Semineri (Mayıs 2012) s. 73-96. Konya, Türkiye.

Özgüler H. 1997. Su, Su kaynakları ve çevresel konular. Meteoroloji Mühendisliği. TMMOB Meteoroloji Mühendisleri Odası Yayın Organı Say1 2, 57-63.

Sağlık A., Sağlık E., Kelkit A. 2014. Peyzaj tasarımında kentsel $1 \mathrm{S1}$ adalarının tespiti ve değerlendirilmesi: Çanakkale kenti örneği. Uluslararası Sanat ve Tasarım Kongresi (20-25 Ekim 2014) s.220-225. İzmir, Türkiye. 
Sütünç H.S. 2012. Ekolojik gösterge olarak peyzaj deseni değişiminin askeri eğitim alanlarında irdelenmesi üzerine bir araştırma. Yüksek Lisans Tezi, AÜ Fen Bilimleri Enstitüsü, 107s. Ankara.

Şahin N. 2013. Kurakçıl peyzaj düzenlemesinde suyun etkin ve akılcı kullanımıXeriscape.Yüksek Lisans Tezi, MSKÜ Fen Bilimleri Enstitüsü, 65 s. Muğla.

Şişman E.E.,Gültürk P. 2014. Tekirdağ kent merkezinde bulunan parkların mevcut durumunun belirlenmesi ve öneri bir peyzaj projesinin hazırlanması. Namık Kemal Üniversitesi Tekirdağ Ziraat Fakültesi Dergisi, 11 (2), 98-109.

Tıkansak T.E. 2014. Kentsel dönüşüm ve sürdürülebilirlik. 1.Uluslararası Kentsel Planlama-Mimarlık-Tasarım Kongresi, Kentsel Dönüşüm Ekonomik, Sosyal ve Fiziksel Yönü (811 Mayıs 2014), 165-174, Kocaeli, Türkiye.

Tülek B. 2008. 'Xeriscape' kurakçıl peyzaj. Yüksek Lisans Semineri, AÜ Fen Bilimleri Enstitüsü, $78 \mathrm{~s}$. Ankara.

URL1, 2016. http://www.scienceandsociety.co.uk/results.asp?i mage $=10301906 \& w w w f l a g=2 \&$ imagepos $=3$

URL2, 2012. T.C Tekirdağ Belediyesi, http://www.tekirdag.bel.tr/default.asp?hedef=sayf alar\&syf $=$ tek $\&$ kay $=4$

URL3, 2016. T.C. Çevre ve Şehircilik Bakanlığı, Tekirdağ Valiliği, Çevre ve Şehircilik İl Müdürlüğü http://www.csb.gov.tr/iller/tekirdag/index.php?Sa $\mathrm{yfa}=$ sayfa $\&$ Tur=webmenu\&Id $=1625$

URL4, 2016. T.C. Orman ve Su İşleri Bakanlı̆̆ı, Meteoroloji Genel Müdürlüğü http://www.mgm.gov.tr/veridegerlendirme/il-veilceler-istatistik.aspx?m=TEKIRDAG\#sfB

Yücel A. S., Morgil İ. 1998. Yüksek öğretimde çevre olgusunun araştırılması. Hacettepe Üniversitesi Eğitim Fakültesi Dergisi, 14, 84-94. 